\title{
Numerical Modeling of Blood Flow in Irregular Stenosed Artery with the Effects of Gravity
}

\author{
Tan Yan Bin ${ }^{a^{*}}$, Norzieha Mustapha ${ }^{a}$ \\ ${ }^{a}$ Department of Mathematical Sciences, Faculty of Science, UniversitiTeknologi Malaysia, 81310 UTM Johor Bahru, Johor, Malaysia \\ *Corresponding author: yanbin43@gmail.com
}

\section{Article history}

Received :18 March 2013

Received in revised form

26 April 2013

Accepted :17 May 2013

\section{Graphical abstract}

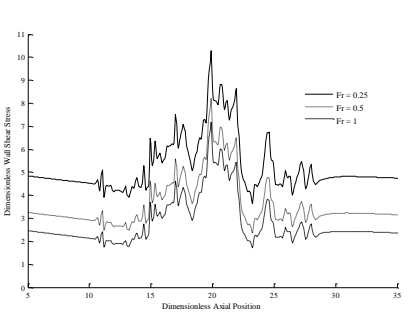

\begin{abstract}
A numerical study on the influences of gravitational force on an unsteady two-dimensional nonlinear model of blood flow through a stenosed artery is presented. Blood flow through the constricted region with an irregular stenosis is considered as incompressible Newtonian fluid. The governing equations are derived from the Navier-Stokes equations, which also comprise a significant term for gravitational force in the axial momentum equation. The numerical method chosen in this study is the finite difference approximations based on Marker and Cell (MAC) method at which governing equations are develop in staggered grids for discretization. The Poisson equation of pressure is solved by successive-overrelaxation (S.O.R.) method. Pressure-velocity corrector is imposed to increase accuracy. Streamlines, wall shear stress and axial velocity profiles are plotted.
\end{abstract}

Keywords: Blood flow; gravity; irregular stenosis; Newtonian fluid; MAC method

\begin{abstract}
Abstrak
Kajian matematik berangka yang dijalankan ini adalah mengenai kesan tarikan gravity ke atas aliran darah melalui arteri berstenosis dengan geometri stenosis tidak teratur. Darah yang mengalir dalam sekmen arteri berstenosis ini dianggap sebagai bendalir Newtonan dan alirannya dianggap tidak mantap, laminar dan berpaksi simetri dalam dua matra. Persamaan Navier-Stokes diterbit dalam koordinat silinder dan ditambahkan dengan terma yang membayangkan tarikan gravit. Kaedah berangka yang dipilih ialah kaedah Marker and Cell (MAC). Corak aliran darah melalui segmen arteri berstenosis tersebut digambarkan dengan garisan-garisan aliran.
\end{abstract}

Kata kunci: Aliran darah; graviti; stenosis tidakteratur; bendalir Newtonian; kaedah MAC

(c) 2013 Penerbit UTM Press. All rights reserved.

\subsection{INTRODUCTION}

Healthcare problems are apparently concerned by people these days. For over centuries, cardiovascular diseases have been noticed as one of the major illnesses where numerous people suffer from them. The cardiovascular system consists of the heart and blood vessels which plays important roles in transportation, protection, and regulation of human body. A pressure gradient is produced as the heart pumps so that blood will flow through vessels throughout the body (Ku [1]). Among the cardiovascular diseases, the familiar ones such as stroke and atherosclerosis are closely related to abnormality, disorder and malfunction of blood flow characteristics in human body. Due to this, blood flow related problems have obtained significant interest by biomedical researchers.

Segmental narrowing of an artery due to substances deposition or intravascular plaques is call an arterial stenosis (Mandal et al. [2]). This may be caused by unhealthy living conditions such as exposure to tobacco smoke, lack of physical activity, and so on. It is always followed by serious changes in blood flow, pressure distribution, wall shear stress, and flow resistance. Once arterial stenosis occurs, atherosclerotic plaques would protrude into lumen of blood vessels. Consequently, resistance is increased; hence blood flow is unsufficient to reach every cells and this resists nutrient suppliment. These could lead to widespread of health disorders which may then worsen to various illnesses. To more serious extent, these abnormalities in blood flow could contribute substantial fatal health risks. Several theoritical and experimental studies by mean of blood flow characteristics with arterial stenosis were done, such as Ling and Atabek [3], Padmanabhan [4], Back et al. [5], Johnston and Kilpatrick [6], Chakravarty and Sannigrahi [7], Ku [1], Jung et al. [8], Mandal [9] and Mustapha et al. ([10], [11], [12]).

Gravitation is a natural fact such that physical bodies are draw to the earth due to masses. Studies suggested that gravity force is one of the bases of regulating blood flow. For space programmes to be carried out safely, studies on physical changes during absence of weight are performed. In space activities, astronauts encounter a condition of microgravity, causing body fluids to distribute more to upper parts of the body which is very different from the condition with gravitation on earth (Kim et al. [13]). However at launch and on return, hypergravity is frequently faced. These types of changes in blood flow velocity due to gravitational force may cause several health problems especially when there are 
unhealthy deposits in blood vessels (Payne [14]; Burrowes et al. [15], [16]). Payne [14] carried out the analysis of the effects of gravity and wall thickness on blood flow behavior. Navier-Stokes equations were derived with additional of gravitational term, $g S$, where $g$ is the gravitational acceleration and $S$ is the vessel slope. The equations are linked to a simple vessel wall model. The result showed that amplitude of the velocity pulse changes with slope.

On the other hand, it is noticed that the acceleration of gravity does not vary only during space activities; even on the earth itself, there are various causes affecting gravitation, such as latitude, altitude, tidal effects, and so forth. For example, at the equator, gravity acceleration gives a value of $9.78 \mathrm{~m} / \mathrm{s}^{2}$ but it becomes $9.832 \mathrm{~m} / \mathrm{s}^{2}$ when shifted to the poles (Boynton [17]). Besides, during postural changes, blood flow distribution and pressure in human body will also be influenced. When a head-up tilt (a test operated to diagnose patients suffered from certain level of dizziness and syncope) is performed, the patient's blood assembles at lower limbs because of gravity during the tilt. This will lead to increment of blood pressure in the lower body and decrement in the head (Heusden et al. [18]; Olufsen et al. [19]).

Mathematical modelling on blood flow in stenosed arteries has been expected to be important in studies of arteriosclerotic plaques and the effects. Various studies formulated an unsteady nonlinear two-dimensional model. It was observed that blood behaves as Newtonian fluid when it flows through wider arteries. But when flowing through a narrower artery at which shear stress is lower, it behaves like a non-Newtonian fluid (Chakravarty and Mandal [20]). In this study, blood flow in arteries is modelled by axisymmetric Navier-Stokes equations; while the artery itself is assumed to be an elastic cylindrical tube composing of Newtonian fluid which is the blood. Analyses of blood flow characteristics under the effects of gravity are taken into consideration. The geometry of stenosis chosen is an irregular stenosis in cylindrical artery vessels following data given by Back et al. [5], which mimics the roughness of real constricted blood vessel surface. Blood flow is assumed to be unsteady, twodimensional, and incompressible. Walls of artery vessels are considered to be elastic and axisymmetric. The numerical method chosen in this study is the finite difference approximations based on Marker and Cell (MAC) method following a MATLAB coding accomplished by Mustapha et al. [11]. Successive-over-relaxation (SOR) method is involved to solve the pressure-Poisson equation.

\subsection{STENOSIS MODEL}

In this study, the profile of stenosis model is chosen to be an irregular stenosis following data developed by Back et al. [5] which imitates the real blood vessel surface roughness.

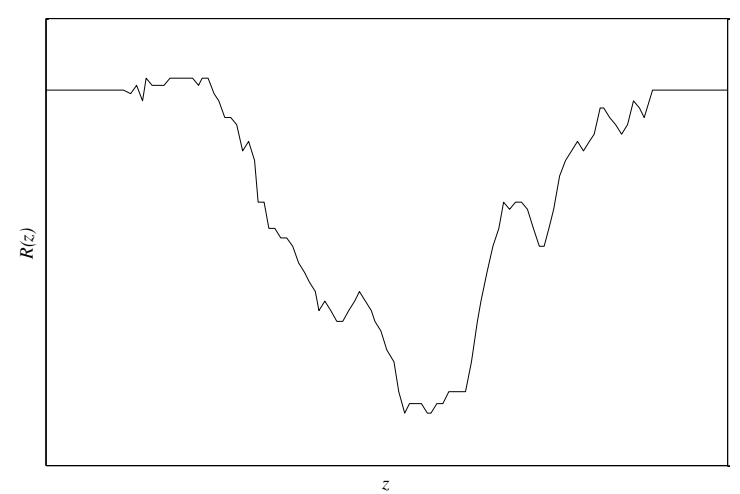

Figure 1 Geometry of the irregular stenosis

\subsection{GOVERNING EQUATIONS}

In this study, streaming blood in the constricted artery segment is accounted to be incompressible, unsteady, laminar, fully-developed, and is modeled as Newtonian fluid. The fundamental governing equations of the studies comprise of the continuity equations and the momentumequations. Conservative forms of the governing equations are presented as follow:

$$
\begin{aligned}
& \tilde{r} \frac{\partial w}{\partial \tilde{z}}+\frac{\partial(u \tilde{r})}{\partial \tilde{r}}=0 \\
& \begin{aligned}
\frac{\partial u}{\partial \tilde{t}}+\frac{\partial u^{2}}{\partial \tilde{r}} & +\frac{\partial(w u)}{\partial \tilde{z}}+\frac{u^{2}}{\tilde{r}} \\
& =-\frac{1}{\rho} \frac{\partial p}{\partial \tilde{r}}+v\left(\frac{\partial^{2} u}{\partial \tilde{r}^{2}}+\frac{1}{\tilde{r}} \frac{\partial u}{\partial \tilde{r}}+\frac{\partial^{2} u}{\partial \tilde{z}^{2}}-\frac{u}{\tilde{r}^{2}}\right)
\end{aligned}
\end{aligned}
$$

$$
\begin{aligned}
\frac{\partial w}{\partial \tilde{t}}+\frac{\partial(w u)}{\partial \tilde{r}} & +\frac{\partial w^{2}}{\partial \tilde{z}}+\frac{w u}{\tilde{r}} \\
= & -\frac{1}{\rho} \frac{\partial p}{\partial \tilde{z}}+v\left(\frac{\partial^{2} w}{\partial \tilde{r}^{2}}+\frac{1}{\tilde{r}} \frac{\partial w}{\partial \tilde{r}}+\frac{\partial^{2} w}{\partial \tilde{z}^{2}}\right)+g \cos \theta
\end{aligned}
$$

The equations are presented in the form of cylindrical polar coordinates system $(r, \theta, z)$, where $z$-axis conveys the longitudinal axis of the studied arterial segment and $r$ conveys the radial. The velocity components are yielded by $(u, v, w)$. Equation (1) is the Continuity Equation while Equations (2) and (3) are the radial and axial momentum equations respectively. $v$ represents the kinematic viscosity $\left(\frac{\mu}{\rho}\right)$ of blood and $p$ represents pressure in segment under study. The axial momentum equations is imposed with a gravitational force term, where $\rho$ is the blood density, $g$ is the gravitational acceleration and $\theta$ is the vertical angle between the direction of vessel and gravity.

To ensure the terms to have same dimension, the equations need to be non-dimensionalised by introducing the following dimensionless quantities:

$$
\begin{aligned}
& t=\tilde{t} \frac{U_{0}}{r_{0}}, r=\frac{\tilde{r}}{r_{0}}, z=\frac{\tilde{z}}{r_{0}}, u=\frac{u}{U_{0}}, w=\frac{w}{U_{0}}, \\
& p=\frac{p}{\rho U_{0}^{2}}, R=\frac{R}{r_{0}}, \operatorname{Re}=\frac{U_{0} r_{0} \rho}{\mu}, F r=\frac{U_{0}^{2}}{g r_{0}}
\end{aligned}
$$

Thus, equations (1) to (3) are non-dimensionalised and become:

$$
\begin{aligned}
& r \frac{\partial w}{\partial z}+\frac{\partial(u r)}{\partial r}=0 \\
& \frac{\partial u}{\partial t}+\frac{\partial u^{2}}{\partial r}+\frac{\partial(w u)}{\partial z}+\frac{u^{2}}{r} \\
&=-\frac{\partial p}{\partial r}+\frac{1}{\operatorname{Re}}\left(\frac{\partial^{2} u}{\partial r^{2}}+\frac{1}{r} \frac{\partial u}{\partial r}+\frac{\partial^{2} u}{\partial z^{2}}-\frac{u}{r^{2}}\right)
\end{aligned}
$$




$$
\begin{aligned}
\frac{\partial w}{\partial t}+\frac{\partial(w u)}{\partial r} & +\frac{\partial w^{2}}{\partial z}+\frac{w u}{r} \\
= & -\frac{\partial p}{\partial z}+\frac{1}{\operatorname{Re}}\left(\frac{\partial^{2} w}{\partial r^{2}}+\frac{1}{r} \frac{\partial w}{\partial r}+\frac{\partial^{2} w}{\partial z^{2}}\right)+\frac{\cos \theta}{F r}
\end{aligned}
$$

where Re is the Reynolds number, $F r$ is the Froude number and $U_{0}$ is the cross sectional average velocity.

\section{M.0 BOUNDARY CONDITIONS}

There is no radial flow along the symmetry axis of the artery, so the normal component of the velocity and the axial velocity gradient of the blood along the axis may be assumed to be zero; that means the shear stress does not exist. These may be stated mathematically as

$u(r, z, t)=0, \frac{\partial w(r, z, t)}{\partial r}=0$ on $r=0$

Blood particles are expected to be adhering to the inner surface of vessel. Hence the velocity boundary conditions on the arterial wall obey the no-slip condition and are taken as

$$
u(r, z, t)=\frac{\partial R}{\partial t}, w(r, z, t)=0 \text { on } r=R(z, t)
$$

The inlet velocity conditions are assumed to have a parabolic profile which resembles the Hagen-Poiseuille flow through a long circular tube even in unsteady state. It is provided with evidence by studies of Rappitsch and Perktold [21] and Stangeby and Eithier [22] as:

$$
w(r, z, t)=2 U_{0}\left(1-\frac{r^{2}}{R^{2}}\right), u(r, z, t)=0 \text { for } z=0
$$

At downstream, the velocity is treated to be zero.

$$
\frac{\partial w(r, z, t)}{\partial z}=0=\frac{\partial u(r, z, t)}{\partial z} \text { for } z=L
$$

where $\mathrm{L}$ is the length of constricted artery segment under study. It is also assumed that no flow takes place when the system is at rest except at the inlet (Tu et al. [23]), described as:

$$
w(r, z, 0)=0, u(r, z, 0)=0, p(r, z, 0)=0 \text { for } z>0
$$

\subsection{BOUNDARY CONDITIONS}

Before solving the governing equations, a radial coordinate transformation is introduced:

$$
x=\frac{r}{R(z, t)}
$$

which has the effect of immobilizing the vessel wall in the transformed coordinate $x$. The dimensionless continuity equation (4), the radial and axial momentum equation (5) - (6) and also the boundary conditions (7) - (11) will be transformed using the radial coordinate transformation and therefore become:

$$
\begin{aligned}
x R \frac{\partial w}{\partial z}-x^{2} \frac{\partial w}{\partial x} \frac{\partial R}{\partial z}+\frac{\partial(u x)}{\partial x}=0 \\
\frac{\partial u}{\partial t}=\frac{x}{R} \frac{\partial R}{\partial t} \frac{\partial u}{\partial x}-\frac{1}{R} \frac{\partial u^{2}}{\partial x}-\frac{\partial(w u)}{\partial z}+\frac{x}{R} \frac{\partial R}{\partial z} \frac{\partial(w u)}{\partial x} \\
-\frac{u^{2}}{x R}-\frac{1}{R} \frac{\partial p}{\partial x}+\frac{1}{\operatorname{Re} R^{2}}\left\{\left[1+\left(x \frac{\partial R}{\partial z}\right)^{2}\right] \frac{\partial^{2} u}{\partial x^{2}}+\right. \\
\left.\left.\frac{1}{x}+2 x\left(\frac{\partial R}{\partial z}\right)^{2}-x R \frac{\partial^{2} R}{\partial z^{2}}\right] \frac{\partial u}{\partial x}-\frac{u}{x^{2}}+R^{2} \frac{\partial^{2} u}{\partial z^{2}}\right\} \\
\frac{\partial w}{\partial t}=\frac{x}{R} \frac{\partial R}{\partial t} \frac{\partial w}{\partial x}-\frac{1}{R} \frac{\partial(w u)}{\partial x}-\frac{\partial w^{2}}{\partial z}+\frac{x}{R} \frac{\partial R}{\partial z} \frac{\partial w^{2}}{\partial x}-\frac{w u}{x R} \\
-\frac{\partial p}{\partial z}+\frac{x}{R} \frac{\partial R}{\partial z} \frac{\partial p}{\partial x}+\frac{1}{\operatorname{Re} R^{2}}\left\{\left[1+\left(x \frac{\partial R}{\partial z}\right)^{2}\right] \frac{\partial^{2} w}{\partial x^{2}}\right. \\
\left.+\left[\frac{1}{x}+2 x\left(\frac{\partial R}{\partial z}\right)^{2}-x R \frac{\partial^{2} R}{\partial z^{2}}\right] \frac{\partial w}{\partial x}+R^{2} \frac{\partial^{2} w}{\partial z^{2}}\right\}+\frac{\cos \theta}{F r}
\end{aligned}
$$

For the boundary conditions, take $R=R(z, t) \neq 0$ and limit $x$ from 0 to 1 . Hence, the boundary conditions (7)-(11) become

$$
\begin{aligned}
& \frac{\partial w(z, x, t)}{\partial x}=0=u(z, x, t) \text { for } x=0 \\
& w(z, x, t)=0, u(z, x, t)=\frac{\partial R}{\partial t} \text { for } x=1 \\
& w(z, x, t)=2 U_{0}\left(1-x^{2}\right), u(z, x, t)=0 \text { for } z=0 \\
& \frac{\partial w(z, x, t)}{\partial z}=0=\frac{\partial u(z, x, t)}{\partial z} \text { for } z=L \\
& w(z, x, 0)=u(z, x, 0), p(z, x, 0)=0 \text { for } z>0
\end{aligned}
$$

\section{[6.0 METHOD OF SOLUTION}

The Marker and Cell (MAC) method (Harlow and Welch [24]) is chosen to solve the governing equations together with the boundary and initial conditions. This is a method based on finite difference scheme in a staggered grid calculating velocities at the edges while pressure at the center as shown in a typical MAC cell as illustrated in Figure 2. The time derivative terms are discretized using first order accurate twolevel forward time differencing formula, while the convective terms in momentum equations are discretized by a hybrid formula consisting of central differencing and second order upwinding. These types of discretizations are chosen for better accuracy (Midya et al. [25]). In this finite difference scheme, we define $x=j \Delta x, z=i \Delta z, t=k \Delta t$, and $p(z, x, t)=p(i \Delta z, j \Delta x, k \Delta t)=p_{i, j}^{k}$, where $k$ refers to the time direction, $\Delta t$ is the time increment, $\Delta x$ and $\Delta z$ are the width and length respectively of the $(i, j)$ th cell. 


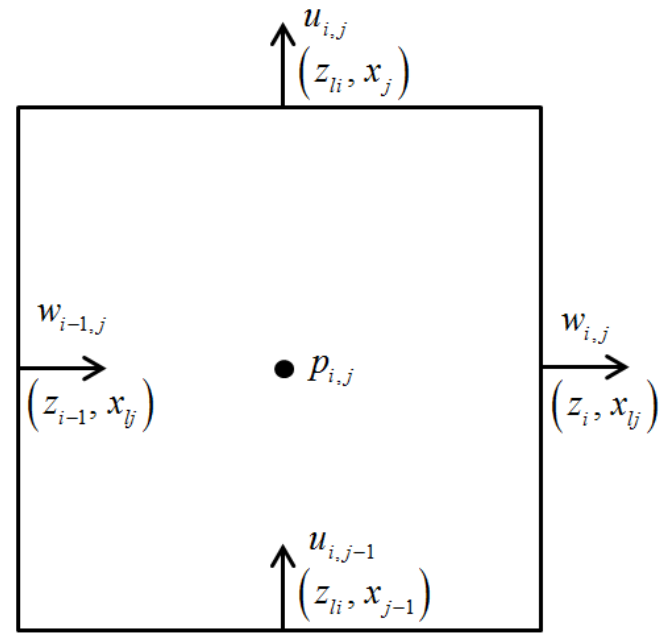

Figure 2 A typical MAC Cell

Discretization of the continuity equation takes place at the location of pressure, $p$, which is also the centre of cell. Its discretized form at the $(i, j)$ th cell is:

$$
\begin{aligned}
x_{l i} R_{l i}^{k}\left(\frac{w_{i, j}^{k}-w_{i-1, j}^{k}}{\Delta z_{i}}\right) & +\left(\frac{x_{j} u_{i, j}^{k}-x_{j-1} u_{i, j-1}^{k}}{\Delta x}\right) \\
& -\left(x_{l j}\right)^{2}\left(\frac{\partial R}{\partial z}\right)_{l i}^{k}\left(\frac{w_{a t}-w_{a b}}{\Delta x}\right)=0
\end{aligned}
$$

where

$$
\begin{aligned}
& w_{a t}=\frac{w_{i, j}^{k}+w_{i-1, j}^{k}+w_{i-1, j+1}^{k}+w_{i, j+1}^{k}}{4}, \\
& w_{a b}=\frac{w_{i, j}^{k}+w_{i-1, j}^{k}+w_{i, j-1}^{k}+w_{i-1, j-1}^{k}}{4}, \text { and } \\
& x_{l j}=x_{j}-\frac{\Delta x}{2}, \quad R^{k}=R\left(z_{l i}\right), \quad z_{l i}=z_{i}-\frac{\Delta z_{i}}{2} .
\end{aligned}
$$

with $\left(z_{l i}, x_{l j}\right)$ and $\left(z_{i}, x_{j}\right)$ represent the coordinates of the cell center and the cell faces respectively, as shown in Figure 2.

Next, the axial momentum equation is rearranged and expressed in finite difference form as

$$
\begin{aligned}
\frac{w_{i, j}^{k+1}-w_{i, j}^{k}}{\Delta t} & =2\left(\frac{P_{i, j}^{k}-P_{i+1, j}^{k}}{\Delta z_{i}+\Delta z_{i+1}}\right) \\
+ & \frac{x_{l j}}{R_{i}^{k}}\left(\frac{\partial R}{\partial z}\right)_{i}^{k}\left(\frac{P_{t}-P_{b}}{\Delta x}\right)+(w m e)_{i, j}^{k}+\frac{\cos \theta}{F r}
\end{aligned}
$$

with

$$
\begin{aligned}
& P_{t}=\frac{\left(P_{i, j}^{k}+P_{i, j+1}^{k}\right) \Delta z_{i+1}+\left(P_{i+1, j}^{k}+P_{i+1, j+1}^{k}\right) \Delta z_{i}}{2\left(\Delta z_{i}+\Delta z_{i+1}\right)}, \\
& P_{b}=\frac{\left(P_{i, j}^{k}+P_{i, j-1}^{k}\right) \Delta z_{i+1}+\left(P_{i+1, j}^{k}+P_{i+1, j-1}^{k}\right) \Delta z_{i}}{2\left(\Delta z_{i}+\Delta z_{i+1}\right)}, \text { and }
\end{aligned}
$$

$$
w m e_{i, j}^{k}=\operatorname{Con} w_{i, j}^{k}+\frac{1}{\operatorname{Re}}\left(\operatorname{Diff} w_{i, j}^{k}\right) .
$$

where $\operatorname{Con} w_{i, j}{ }^{k}$ and $\operatorname{Diff} w_{i, j}{ }^{k}$ describes the convective and diffusive terms of the axial momentum equation at $k$-th time level at the $(i, j)$ th cell. The discretized expressions for these terms are:

$$
\begin{aligned}
\operatorname{Con} w_{i, j}^{k} & =\frac{x_{l j}}{R_{i}^{k}}\left(\frac{\partial R}{\partial t}\right)_{i}^{k}\left(\frac{w_{i, j+1}^{k}-w_{i, j-1}^{k}}{2 \Delta x}\right) \\
& -\frac{1}{R_{i}^{k}}\left[(1-\beta) \frac{w_{t} u_{t}-w_{b} u_{b}}{\Delta x}+\beta \frac{w_{t} \phi_{w t}-w_{b} \phi_{w b}}{\Delta x}\right] \\
& -\left[(1-\beta) \frac{w_{r}^{2}-w_{l}^{2}}{\Delta z}+\beta \frac{w_{r} \phi_{w r}-w_{l} \phi_{w l}}{\Delta z}\right]-\frac{w_{i, j}^{k} u_{m}}{x_{l j} R_{i}^{k}} \\
+ & \frac{x_{l j}}{R_{i}^{k}}\left(\frac{\partial R}{\partial z}\right)_{i}^{k}\left[(1-\beta) \frac{w_{t}^{2}-w_{b}^{2}}{\Delta x}+\beta \frac{w_{t} \phi_{w t}-w_{b} \phi_{w b}}{\Delta x}\right]
\end{aligned}
$$

$$
\begin{gathered}
\operatorname{Diff}_{i, j}^{k}=\frac{1}{\left(R_{i}^{k}\right)^{2}}\left\{\left[1+\left\{x_{l j}\left(\frac{\partial R}{\partial z}\right)_{i}^{k}\right\}^{2}\right] \frac{w_{i, j+1}^{k}-2 w_{i, j}^{k}+w_{i, j-1}^{k}}{\Delta x^{2}}\right. \\
+\left[\frac{1}{x_{l j}}+2 x_{l j}\left[\left(\frac{\partial R}{\partial z}\right)_{i}^{k}\right]^{2}-x_{l j} R_{i}^{k}\left(\frac{\partial^{2} R}{\partial z^{2}}\right)_{i}^{k}\right] \frac{w_{i, j+1}^{k}-w_{i, j-1}^{k}}{2 \Delta x} \\
\left.+2\left(R_{i}^{k}\right)^{2} \frac{w_{i+1, j}^{k} \Delta z_{i-1}-w_{i, j}^{k}\left(\Delta z_{i}+\Delta z_{i-1}\right)+w_{i-1, j}^{k} \Delta z_{i}}{\Delta z_{i} \Delta z_{i-1}\left(\Delta z_{i}+\Delta z_{i-1}\right)}\right\}
\end{gathered}
$$

The convective term as in equation (29) is differenced with a combination of central differencing and second order upwind schemes. As seen equation (29), a combination factor, $\beta$, is introduced. It is determined from numerical stability. When $\beta=0$, the scheme becomes central differencing and when $\beta=1$, the scheme approches second upwind differencing.

For the axial momentum equation, the differential symbols are defined by:

$$
\begin{aligned}
& w_{r}=\left(w_{i, j}^{k}+w_{i+1, j}^{k}\right) / 2 ; w_{l}=\left(w_{i, j}^{k}+w_{i-1, j}^{k}\right) / 2 ; \\
& w_{t}=\left(w_{i, j}^{k}+w_{i, j+1}^{k}\right) / 2 ; w_{b}=\left(w_{i, j}^{k}+w_{i, j-1}^{k}\right) / 2 ; \\
& u_{t}=\left(u_{i, j}^{k}+u_{i+1, j}^{k}\right) / 2 ; u_{b}=\left(u_{i, j-1}^{k}+u_{i+1, j-1}^{k}\right) / 2 ; \\
& u_{m}=\left(u_{t}+u_{b}\right) / 2
\end{aligned}
$$

where the suffixes $r, l, t$ and $b$ represents right, left, top and bottom middle positions of the cell faces while suffix $m$ represents the middle of the cell faces.

Then, the momentum fluxes, $\phi$, for axial momentum are expressed as:

if $w_{r} \geq 0, \phi_{w r}=w_{i, j}^{k}$; if $w_{r}<0, \phi_{w r}=w_{i+1, j}^{k}$; 
if $w_{l} \geq 0, \phi_{w l}=w_{i-1, j}^{k}$; if $w_{l}<0, \phi_{w l}=w_{i, j}^{k}$;

if $w_{t} \geq 0, \phi_{w t}=w_{i, j}^{k}$; if $w_{t}<0, \phi_{w r}=w_{i, j+1}^{k}$;

if $w_{b} \geq 0, \phi_{w b}=w_{i, j-1}^{k}$; if $w_{b}<0, \phi_{w b}=w_{i, j}^{k}$.

Similarly,

if $u_{t} \geq 0, \phi_{u t}=w_{i, j}^{k} ;$ if $u_{t}<0, \phi_{u t}=w_{i, j+1}^{k}$;

if $u_{b} \geq 0, \phi_{u b}=w_{i, j-1}^{k}$; if $u_{b}<0, \phi_{u b}=w_{i, j}{ }^{k}$.

For radial momentum equation, the finite difference form is expressed as:

$\frac{u_{i, j}^{k+1}-u_{i, j}^{k}}{\Delta t}=\frac{1}{R_{l i}^{k}}\left(\frac{P_{i, j}^{k}-P_{i, j+1}^{k}}{\Delta x}\right)+u m e_{i, j}^{k}$

where

$u m e_{i, j}^{k}=\operatorname{Con} u_{i, j}^{k}+\frac{1}{\operatorname{Re}}\left(\operatorname{Diff} u_{i, j}^{k}\right)$.

$\operatorname{Con} u_{i, j}^{k}$ and Diff $u_{i, j}^{k}$ are convective and diffusive terms of the radial momentum equation at $k$-th time level at the $(i, j)$ th cell. The terms are differenced in the same manner as in the axial momentum equation where

$$
\begin{gathered}
\operatorname{Con} u_{i, j}^{k}=\frac{x_{j}}{R_{l i}^{k}}\left(\frac{\partial R}{\partial z}\right)_{l i}^{k}\left[(1-\beta) \frac{w_{t} u_{t}-w_{b} u_{b}}{\Delta x}\right. \\
\left.+\beta \frac{w_{t} \phi_{u t}-w_{b} \phi_{u b}}{\Delta x}\right]+\frac{x_{j}}{R_{l i}^{k}}\left(\frac{\partial R}{\partial t}\right)_{l i}^{k}\left[\frac{u_{i, j+1}^{k}-u_{i, j-1}^{k}}{2 \Delta x}\right] \\
-\frac{1}{R_{l i}^{k}}\left[(1-\beta) \frac{u_{t}^{2}-u_{b}^{2}}{\Delta x}+\beta \frac{u_{t} \phi_{u t}-u_{b} \phi_{u b}}{\Delta x}\right] \\
-\left[(1-\beta) \frac{u_{r} w_{r}-u_{l} w_{l}}{\Delta z_{i}}+\beta \frac{w_{r} \phi_{u r}-w_{l} \phi_{u l}}{\Delta z_{i}}\right]-\frac{\left(u_{i, j}^{k}\right)^{2}}{x_{j} R_{l i}^{k}} \\
\operatorname{Diff} u_{i, j}^{k}=\frac{1}{\left(R_{l i}^{k}\right)^{2}}\left\{\left[1+\left(x_{j}\left(\frac{\partial R}{\partial z}\right)_{l i}^{k}\right)^{2}\right] \frac{u_{i, j+1}^{k}-2 u_{i, j}^{k}+u_{i, j-1}^{k}}{\Delta x^{2}}\right. \\
+\frac{u_{i, j+1}^{k}-u_{i, j-1}^{k}}{2 \Delta x}\left[\frac{1}{x_{j}}+2 x_{j}\left(\left(\frac{\partial R}{\partial z}\right)_{l i}^{k}\right)^{2}\right. \\
\left.\left.\quad-x_{j}\left(R_{l i}^{k}\right)^{2}\left(\frac{\partial^{2} R}{\partial z^{2}}\right)_{l i}^{k}\right]+\left(R_{l i}^{k}\right)^{2}\left(\frac{\partial^{2} u}{\partial z^{2}}\right)_{i, j}^{k}-\frac{u_{i, j}^{k}}{x_{j}^{2}}\right\}
\end{gathered}
$$

Next, the Poisson equation for pressure is gained by coupling and combining the discretized form of the continuity and momentum equations. After rearranging, the final form of Poisson equation for pressure would be:

$$
\begin{aligned}
& \frac{D i v_{i, j}^{k+1}-D i v_{i, j}^{k}}{\Delta t}=A_{i, j} P_{i, j}^{k}+B_{i, j} P_{i+1, j}^{k}+C_{i, j} P_{i-1, j}^{k} \\
& +D_{i, j} P_{i, j+1}^{k}+E_{i, j} P_{i, j-1}^{k}+F_{i, j} P_{i+1, j+1}^{k}+G_{i, j} P_{i+1, j-1}^{k} \\
& +H_{i, j} P_{i-1, j-1}^{k}+S_{i, j} P_{i-1, j+1}^{k}+x_{l j} R_{l i}^{k}\left(\frac{w m e_{i, j}^{k}-w m e_{i-1, j}^{k}}{\Delta z_{i}}\right) \\
& +\frac{x_{j} u m e_{i, j}^{k}-x_{j-1} u m e_{i, j-1}^{k}}{\Delta x}
\end{aligned}
$$

Here, $D i v_{i, j}{ }^{k}$ represents the discretized form of divergence of velocity field at the $(i, j)$ th cell and are describes as:

$$
\begin{aligned}
& \operatorname{Div}_{i, j}^{k+1}=x_{l j} R_{l i}^{k}\left(\frac{w_{i, j}^{k+1}-w_{i-1, j}^{k+1}}{\Delta z_{i}}\right)+\frac{x_{j} u_{i, j}^{k+1}-x_{j-1} u_{i, j-1}^{k+1}}{\Delta x} \\
& \operatorname{Div}_{i, j}^{k}=x_{l j} R_{l i}^{k}\left(\frac{w_{i, j}^{k}-w_{i-1, j}^{k}}{\Delta z_{i}}\right)+\frac{x_{j} u_{i, j}^{k}-x_{j-1} u_{i, j-1}^{k}}{\Delta x}
\end{aligned}
$$

Then, the expressions for $A, B, C, D, E, F, G, H, S$ are given as follow:

$$
\begin{aligned}
& A_{i, j}=\frac{x_{j} R_{l i}^{k}}{\Delta z_{i} \Delta z_{t}}+\frac{x_{j} R_{l i}^{k}}{\Delta z_{i} \Delta z_{b}}+\frac{x_{j}}{R_{l i}^{k} \Delta x^{2}}+\frac{x_{j-1}}{R_{l i}^{k} \Delta x^{2}} ; \\
& B_{i, j}=-\frac{x_{j} R_{l i}^{k}}{\Delta z_{i} \Delta z_{t}} ; C_{i, j}=-\frac{x_{j} R_{l i}^{k}}{\Delta z_{i} \Delta z_{b}} ; \\
& D_{i, j}=\frac{x_{l j}^{2} R_{l i}^{k}}{4 \Delta x \Delta z_{i}}\left(\frac{\Delta z_{i+1}}{R_{i}^{k} \Delta z_{t}}\left(\frac{\partial R}{\partial z}\right)_{i}^{k}-\frac{\Delta z_{i-1}}{R_{i-1}^{k} \Delta z_{b}}\left(\frac{\partial R}{\partial z}\right)_{i-1}^{k}\right)-\frac{x_{j}}{R_{l i}^{k} \Delta x^{2}} ; \\
& E_{i, j}=\frac{x_{l j}^{2} R_{l i}^{k}}{4 \Delta x \Delta z_{i}}\left(\frac{\Delta z_{i-1}}{R_{i-1}^{k} \Delta z_{b}}\left(\frac{\partial R}{\partial z}\right)_{i-1}^{k}-\frac{\Delta z_{i+1}}{R_{i}^{k} \Delta z_{t}}\left(\frac{\partial R}{\partial z}\right)_{i}^{k}\right)-\frac{x_{j-1}}{R_{l i}^{k} \Delta x^{2}} ; \\
& F_{i, j}=\frac{x_{l j}^{2} R_{l i}^{k}}{4 R_{i}^{k} \Delta x \Delta z_{t}}\left(\frac{\partial R}{\partial z}\right)_{i}^{k} ; G_{i, j}=-F_{i, j} ; \\
& H_{i, j}=\frac{x_{l j}^{2} R_{l i}^{k}}{4 R_{i-1} \Delta x \Delta z_{b}}\left(\frac{\partial R}{\partial z}\right)_{i-1}^{k} \text { and } S_{i, j}=-H_{i, j} . \\
& \text { where } \Delta z_{t}=\frac{\Delta z_{i}+\Delta z_{i+1}}{2} \text { and } \Delta z_{b}=\frac{\Delta z_{i}+\Delta z_{i-1}}{2} .
\end{aligned}
$$

The next step is to solve the Poisson equation for pressure (35) by the successive over-relaxation (SOR) method with a certain number of iterations. This is to get the intermediate pressure field at the $n$th time step. Here, the value of the over-relaxation parameter is taken to be 1.2 .

\subsection{Pressure and Velocity Corrections}

After solving the Poisson equation of pressure, the pressure obtained is an intermediate hence inaccurate. The velocities obtained do not satisfy the continuity equation. So, pressure and velocities should undergo a correction stage to get better accuracy. Here, a pressure-correction relation is introduced:

$$
P_{i, j}^{n}=P_{i, j}^{*}+\omega_{2} \Delta P_{i, j}
$$


where $P_{i, j}^{*}$ is the intermediate pressure obtained from the Poisson equation of pressure, $\omega_{2}$ (which is $\leq 0.5$ ) is an under relaxation parameter and $\Delta P_{i, j}$ is the pressure error term described as

$\Delta P_{i, j}=-\frac{D i v_{i, j}^{*}}{\Delta t A_{i, j}}$

where $D i v_{i, j}^{*}$ is the divergence value of velocity field at the $(i, j)$ th cell. Next, the velocity correction formulas are

$w_{i, j}^{n+1}=w_{i, j}^{*}+\frac{\Delta t \Delta P_{i, j}}{0.5\left(\Delta z_{i+1}+\Delta z_{i}\right)}$,

$w_{i-1, j}^{n+1}=w_{i-1, j}^{*}-\frac{\Delta t \Delta P_{i, j}}{0.5\left(\Delta z_{i+1}+\Delta z_{i}\right)}$,

$u_{i, j}^{n+1}=u_{i, j}^{*}+\frac{\Delta t \Delta P_{i, j}}{R_{l i} \Delta x}$,

and $u_{i, j-1}^{n+1}=u_{i, j-1}^{*}-\frac{\Delta t \Delta P_{i, j}}{R_{l i} \Delta x}$

where $w_{i, j}^{*}, w_{i-1, j}^{*}, u_{i, j}^{*}$ and $u_{i, j-1}^{*}$ are the updated velocity components obtained after solving the Poisson equation of pressure.

\subsection{Stability Restriction}

For the numerical computation to be stable, several considerations need to be made. Restrictions on the mesh sizes, $\Delta z$ and $\Delta x$, and time interval $\Delta t$ are imposed. Markhan and Proctor [26] suggested that, with relation to fluid convection, the fluid cannot pass through more than one cell in each time step. So the time step must obey the following inequality:

$$
\Delta t_{1} \leq \operatorname{Min}\left[\frac{\Delta z_{i}}{|w|}, \frac{\Delta x}{|u|}\right]_{i j} .
$$

As suggested by Welch et al. [27], momentum must not diffuse more than one cell in each time step. The second stability restriction, which is related to the viscous effects of fluid, is suggested by Hirt [28] such that

$$
\Delta t_{2} \leq \operatorname{Min}\left[\frac{\operatorname{Re}}{2} \frac{\Delta x^{2} \Delta z_{i}^{2}}{\left(\Delta x^{2}+\Delta z_{i}^{2}\right)}\right]_{i j} .
$$

Combining and simplifying inequalities (44) and (45), the time step should be concluded to obey the following inequality:

$$
\Delta t=c \operatorname{Min}\left[\Delta t_{1}, \Delta t_{2}\right]_{i j}
$$

where the constant $c$ (lying between 0.2 and 0.5 ) is added as a considerable computational saving.
Other than that, the combination factor, $\beta$, should be picked according to the following inequality:

$$
1 \geq \beta \geq \operatorname{Max}\left[\left|\frac{w \Delta t}{\Delta z_{i}}\right|,\left|\frac{u \Delta t}{\Delta x}\right|\right]_{i j}
$$

However, this inequality yields only a very small and considered not so significant. It can be improved by multiplying a factor of 1.2 as a safety measure.

\subsection{RESULTS AND DISCUSSIONS}

The imposed numerical algorithm based on Marker and Cell (MAC) method is validated by Mustapha et al. ([10]-[12]) using Matlab Programming software. In order to perform numerical computations of the desired quantities of major physiological significance, the following parameter values have been made use of:

$$
\begin{gathered}
\rho=1.06 \times 10^{3} \mathrm{~kg} \mathrm{~m}^{-3} ; \omega=2 \pi f_{p} ; \\
f_{p}=1.2 \mathrm{~Hz} ; \theta=0^{0} ; U_{0}=0.5 ; \operatorname{Re}=50
\end{gathered}
$$

The numerical results presented in graphs are shown in this section.

\subsection{Streamlines For Different Values Of Froude Numbers}

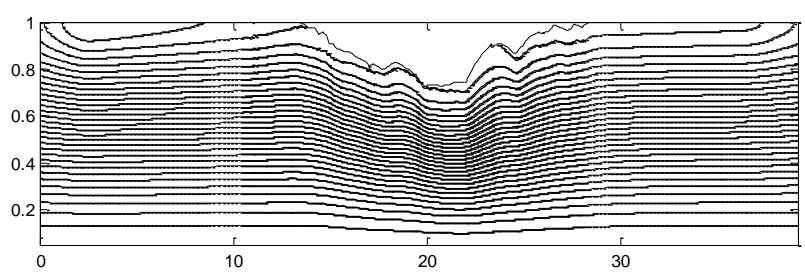

Figure 3 Patterns of streamlines for $\mathrm{Fr}=0.25$

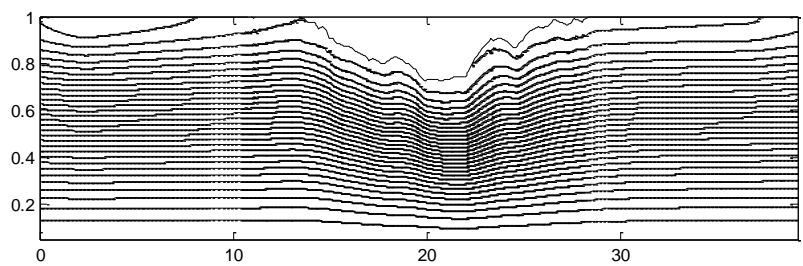

Figure 4 Patterns of streamlines for $\mathrm{Fr}=0.5$

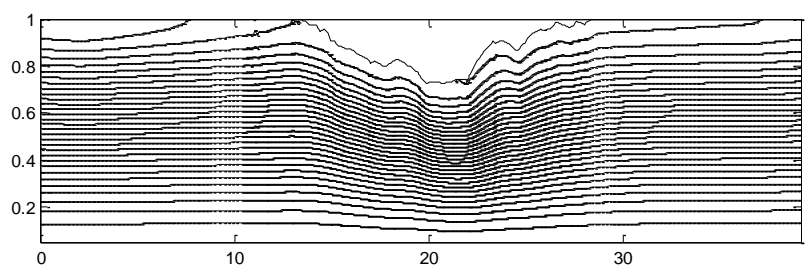

Figure 5 Patterns of streamlines for $\mathrm{Fr}=1$

Figures 3-5 show the patterns of streamlines regarding blood flow through the constricted arterial segment with single irregular stenosis. Variation of the dimensionless Froude number represents values of gravitational force where lower value of Froude number indicates higher value of gravity. From the streamlines plotted, it it noticed that the streamlines do not overlap. This means that at each point there 
is only one velocity. No recirculation region is observed for these 3 values of Froude numbers with this mild stenosis.

\subsection{Wall Shear Stress}

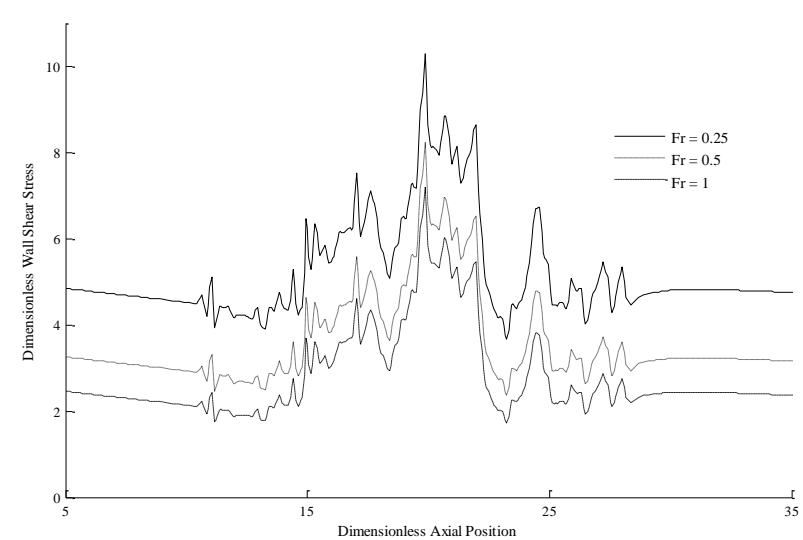

Figure 6 Variations of wall shear stress at different values of Froude numbers

Variations of wall shear stress comparing different values of Froude numbers along the dimensionless axial position are demonstrated in Figure 4. Wall shear stress is influenced by different values of gravity. It is clearly noticed that at lower Froude number (meaning higher gravitational force), wall shear stress is relatively higher.

\subsection{Axial Velocity}

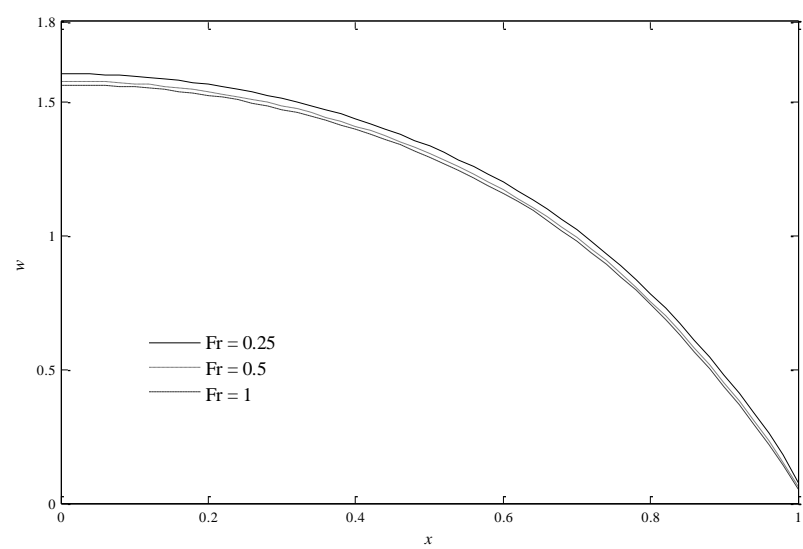

Figure 7 Axial velocity profiles for different values of Froude numbers at $z=20.16$

Figure 5 illustrates how gravity influences axial velocity profiles of the constricted arterial region. The velocity profiles are analyzed at position $z=20.16$ which is one of the critical heights of the stenosis. The velocities decrease from their individual maximum. Comparing the graphs, axial velocity for $\mathrm{Fr}=0.25$ (highest relative gravitational force) is noticed to have the relatively highest individual maxima, and vice versa. Hence, it can be concluded that axial velocity rises upon increment of gravity.

\subsection{CONCLUSION}

An unsteady two dimensional nonlinear model of blood flow through an irregular stenosed arterial segment is developed to study the effects of gravitation on blood flow. Blood is considered as an incompressible Newtonian fluid. The governing equations are non-dimensionalised and transformed using radial transformation. Then, they are solved using the finite difference approximations based on Marker and Cell (MAC) method. Values of gravitation is described dimensionlessly via different values of Froude number. Lower value of Froude number represents a condition with higher gravitational force and vice versa.

Streamlines of blood flow through the constricted arterial segment are plotted (Figures 3-5) to analyse differences of the flow patterns. Variations of wall shear stress along the constricted region is also plotted (Figure 6). Then in Figure 7, axial velocity profiles for different values of Froude numbers are plotted. As a summary, wall shear stress and axial velocity at lower Froude number (higher gravitational force) give higher values than that of a condition at higher Froude number.

\section{Acknowledgement}

The first author would like to thank the Ministry of Higher Education Malaysia for financial support under MyBrain 15.

\section{References}

[1] Ku, D. N. 1997. Blood Flow in Arteries. Annu. Rev. Fluid Mechanics. 29: 399-434.

[2] Mandal, P. K., Chakravarty, S., Mandal, A., and Amin, N. 2007. Effect of Body Acceleration on Unsteady Pulsatile Flow of NonNewtonian Fluid through a Stenosed Artery. Applied Mathematics and Computation. 189: 766-779.

[3] Ling, S. C., \& Atabek, H. B. 1972. A Nonlinear Analysis of Pulsatile Flow in Arteries. J. Fluid. Mech. 55: 493-511.

[4] Padmanabhan, N. 1980. Mathematical Model of Arterial Stenosis. Med. \& Biol. Eng. \& Comput. 18: 281-286.

[5] Back, L. H., Cho, Y. I., Crawford, D. W. and Cuffel, R. F. Effect of mild atherosclerosis on flow resistance in a coronary artery casting of man. ASME J. Biomech. Eng. 1984. 106: 48-53.

[6] Johnston, P. R. and Kilpatrick, D. 1991. Mathematical modelling of flow through an irregular arterial stenosis. J. Biomech. 24: 10691077.

[7] Chakravarty, S. and Sannigrahi, A. K. 1994. Effects of body acceleration on Blood Flow in an Irregular Stenosed Artery. Mathl. Comput. Modelling. 19(5): 93-103.

[8] Jung, H., Choi, J. W., and Park, C. G. 2004. Asymmetric Flows of Non-Newtonian Fluids in Symmetric Stenosed Artery. KoreaAustralia Rheology Journal. 16(2): 101-108.

[9] Mandal, P. K. 2005. An Unsteady Analysis of Non-Newtonian Blood Flow through Tapered Arteries with a Stenosis. International Journal of Non-Linear Mechanics. 40: 151-164.

[10] Mustapha, N., Chakravarty, S., Mandal, P. K., \& Amin, N. 2008. Unsteady Response of Blood Flow through a Couple of Irregular Arterial Constrictions to Body Acceleration. Journal of Mechanics in Medicine and Biology. 8(3): 395-420.

[11] Mustapha, N., Amin, N., Chakravarty, S., and Mandal, P. K. 2009. Unsteady Magnetohydrodynamic Blood Flow Through Irregular Multi-stenosed Arteries. Computers in Biology and Medicine. 39: 896-906.

[12] Mustapha, N., Mandal, P. K., Johnston, P. R., and Amin, N. A. 2010. Numerical Simulation of Unsteady Blood Flow Through Multi-Irregular Arterial Stenoses. Applied Mathematical Modelling. 34: 1559-1573.

[13] Kim, C. S., Kiris, C., Kwak, D. and David, T. 2006. Numerical Simulation of Local Blood Flow in the Carotid and Cerebral Arteries under Altered Gravity. Journal of Biomechanical Engineering. 128: 194-202.

[14] Payne, S. J. 2004. Analysis of the Effects of Gravity and Wall Thickness in a Model of Blood Flow Through Axisymmetric Vessels. Medical \& Biological Engineering \& Computing. 42: 799-806.

[15] Burrowes, K. S., Hunter, P. J. and Tawhai, M. H. 2005. Investigation of the Relative Effects of Vascular Branching Structure and Gravity on Pulmonary Arterial Blood Flow Heterogeneity via an Image-based Computational Model. Academic Radiology. 12(11): 1464-1474. 
[16] Burrowes, K. S. and Tawhai, M. H. 2006. Computational Predictions of Pulmonary Blood Flow Gradients: Gravity Versus Structure. Respiratory Physiology \& Neurobiology. 154: 515-523.

[17] Boynton, R. 2001. Precise Measurement of Mass.

[18] Heusden, K., Gisolf, J., Stok, W. J., Dijkstra, S., and Karemaker, J. M. 2006. Mahtematical Modeling of Gravitational Effects on the Circulation: Importance of the Time Course of Venous Pooling and Blood Volume Changes in the Lungs. AJP - Heart and Circulatory Physiology. 291: H2152-H2165.

[19] Olufsen, M. S., Smith, B., Mehlsen, J. and Ottesen, J. 2011. The impact of gravity during head-up tilt. $33^{\text {rd }}$ Annual International Conference if the IEEE EMBS.

[20] Chakravarty, S. and Mandal, P. K. 1996. A Nonlinear TwoDimensional Model of Blood Flow in an Overlapping Arterial Stenosis Subjected to Body Acceleration. Mathl. Comput. Modelling. 24(1): 43-58.

[21] Rappitsch, G. and Perktold, K. 1996. Computer simulation of convective diffusion processes in large arteries. J. Biomech. Eng. 124: $1-8$.
[22] Stangeby, D. K. and Eithier, C. R. 2002. Computational Analysis of Coupled Blood Wall Arterial LDL Transport. J. Biomech Eng. 124: $1-8$.

[23] Tu, C., Deville, M., Dheur, L. and Vanderschuren, L. 1992. Finite Element Simulation of Pulsatile Flow Through Arterial Stenosis. $J$. Biomech. 25: 1141-1152.

[24] Harlow, F. H. and Welch, J. E. 1965. Numerical Calculation of Time-dependent Viscous Incompressible Flow of Fluid with Free Surface. Phys. Fluids. 8(12): 2182-2189.

[25] Midya, C., Layek, G. C., Gupta, A. S. and Mahapatra, T. R. 2003. Magnetohydrodynamic Viscous Flow Separation in a Channel with Constrictions. ASME J. Fluids Engng. 125: 952-962.

[26] Markham, G. and Proctor, M. V. 1983. C.E.G.B. Report TRPD/L/0063/M82

[27] Welch, J. E., Harlow, F. H., Shannon, J. P. and Daly, B. J. 1996. The MAC method. Los Alamos Scientific Lab, Report LA-3425, Los Alamos. 1996.

[28] Hirt, C. W. 1968. Heuristic stability theory for finite difference equations. J. Comput. Phys. 2: 339 